\title{
Effects of surface conditioning on repair bond strengths of non-aged and aged microhybrid, nanohybrid, and nanofilled composite resins
}

\author{
Margareta Rinastiti • Mutlu Özcan • \\ Widowati Siswomihardjo • Henk J. Busscher
}

Received: 3 November 2009/Accepted: 5 May 2010/Published online: 25 May 2010

(C) The Author(s) 2010. This article is published with open access at Springerlink.com

\begin{abstract}
This study evaluates effects of aging on repair bond strengths of microhybrid, nanohybrid, and nanofilled composite resins and characterizes the interacting surfaces after aging. Disk-shaped composite specimens were assigned to one of three aging conditions: (1) thermocycling $(5,000 \times$, $5-55^{\circ} \mathrm{C}$ ), (2) storage in water at $37^{\circ} \mathrm{C}$ for 6 months, or (3) immersion in citric acid at $37^{\circ} \mathrm{C}$, pH 3 for 1 week; a nonaged group acted as the control. Two surface conditionings were selected: intermediate adhesive resin application (IARapplication) and chairside silica coating followed by silanization and its specific IAR-application (SC-application). Composite resins, of the same kind as their substrate, were adhered onto the substrates, and repair shear bond strengths were determined, followed by failure type evaluation. Filler particle exposure was determined by $\mathrm{X}$-ray photoelectron
\end{abstract}

M. Rinastiti $\cdot$ H. J. Busscher

Department of BioMedical Engineering,

University Medical Center Groningen, University of Groningen,

Groningen, The Netherlands

M. Rinastiti $(\bowtie)$

Department of Conservative Dentistry, Faculty of Dentistry, Gadjah Mada University,

Denta, Sekip Utara,

Yogyakarta 55218, Indonesia

e-mail: rinastiti@gmail.com

\section{M. Özcan}

Dental Materials Unit, Center for Dental and Oral Medicine, Clinic for Fixed and Removable Prosthodontics and Dental Materials Science, University of Zurich,

Zurich, Switzerland

W. Siswomihardjo

Department of Biomaterials, Faculty of Dentistry,

Gadjah Mada University,

Yogyakarta, Indonesia spectroscopy and surface roughness analyzed using scanning electron and atomic force microscopy. Surface roughness increased in all composite resins after aging, but filler particle exposure at the surface only increased after thermocycling and citric acid immersion. Composite resin type, surface conditioning, and aging method significantly influenced the repair bond strengths ( $p<0.05$, three-way analysis of variance) with the least severe effects of water storage. Repair bond strengths in aged composite resins after IAR-application were always lower in non-aged ones, while SC-application led to higher bond strengths than IAR-application after thermocycling and water storage. In addition, SC-application led to more cohesive failures than after IAR-application, regardless the aging method.

Keywords Aged composite resin repair .

Intermediate adhesive resin - Microhybrid composite resin . Nanofilled composite resin - Nanohybrid composite resin . Silica coating

\section{Introduction}

Advances in adhesive technologies strongly influenced current concepts in restorative dentistry with the goal of conserving healthy dental tissues and reducing the number of interventions needed [1, 2]. Application of resin-based composites does not require mechanical retention enabling minimal invasive treatment [3]. However, dynamic conditions in the oral environment, such as $\mathrm{pH}$ changes in saliva, diet, and rapid temperature alterations, may degrade the composite resin $[4,5]$. In vivo aging involves various phenomena including discoloration, microleakage, wear, ditching at the margins, delamination, or simply fracture and may ultimately require replacement [6-8]. Total replacement of a restoration is the 
most common procedure in daily clinical practice [6]. However, this approach may be regarded as overtreatment since in most cases, a large portion of the restoration is clinically and radiographically intact. Complete removal of a restoration inevitably leads to weakening of the tooth structure, unnecessary grinding of sound dental tissues, and sometimes repeated injuries to the pulp [9, 10]. For this reason, repair of existing restorations through relayering is considered as an alternative for total replacement [6]. The success of composite-to-composite bonding in repair through relayering depends on the condition of the composite resin surface, including its composition [11], roughness [12], wettability [13], and the surface conditioning methods applied $[11,14-16]$.

Due to aging of the composite resin surface in the dynamic oral environment, the adhesive strength of composite-tocomposite restorations decreases by $25 \%$ to $80 \%$ compared to their original strength $[16,17]$. Therefore, various surface conditioning methods have been developed to improve adhesion between aged and non-aged composite resins. The use of an intermediate adhesive resin is known to enhance the repair bond strength significantly $[14,16]$, while also chairside air-borne particle abrasion with small silica-coated alumina particles followed by silanization has been reported to yield a significant increase in composite-to-composite bonding $[12,15,18]$, but there is no consensus about possible benefits of the use of silica coating over application of intermediate adhesive resins for aged composite resins.

In laboratory studies, aging of composite resins has been simulated by storage in water $[19,20]$, citric acid immersion $[15,21]$, or subjecting them to thermocycling $[22,23]$. Among all these methods, water storage is considered to have detrimental effects on the composite resin surface due to hydrolysis and release of filler particles as well as water uptake in the resin matrix [24, 25]. Thermocycling generates stresses due to differences between thermal expansion of various materials involved in a restoration that could result in bond failure at the tooth-restoration or filler-matrix interface [26]. Aging of composite resins through citric acid challenges has not been frequently applied but may be advocated to mimic effects of acidic food and beverages. Citric acid immersion is known to cause release of filler particles, similar as observed after water storage [15]. Composite-to-composite bonding after aging has been investigated in several studies [27, 28] without a common consensus on which aging method represents the worst case or clinically most relevant scenario.

The objectives of this study were to compare the strengths of composite-to-composite bonding for microhybrid, nanohybrid, and nanofilled composite resins after different aging methods and to analyze the effect of different aging conditions on the composite surface. The null hypothesis to be tested was that aging conditions would decrease the repair bond strength in all types of composite resins.

\section{Materials and methods}

Composite resins, specimen preparation, and aging conditions

Product names, manufacturers, chemical compositions, abbreviations, and batch numbers of the materials used in this study are listed in Table 1. A flow diagram of the experimental design and techniques applied is presented in Fig. 1.

Disk-shaped specimens were made by placing unpolymerized composite resins into cylindrical undercut cavities (diameter $5.5 \mathrm{~mm}$, thickness $3.5 \mathrm{~mm}$ ) prepared of polymethylmethacrylate surrounded by a polyvinylchloride cylinder (three specimens per cylinder). The unpolymerized composite resins were packed in increments of $2 \mathrm{~mm}$ into the cavities with a hand instrument and photo-polymerized. Each increment was photo-polymerized with a halogen photo-polymerization unit (Optilux 501, Kerr Co., Orange, CA, USA) for $20 \mathrm{~s}(\mathrm{G}, \mathrm{TE}$, and FS) or $40 \mathrm{~s}(\mathrm{AS})$ at a distance of $2 \mathrm{~mm}$ from the surface. Light intensity was higher than $400 \mathrm{~mW} / \mathrm{cm}^{2}$, as verified by a radiometer (Demetron LC, Kerr Co.), after every six specimens. During final photo-polymerization, the top surface layer was covered with a $100-\mu \mathrm{m}$ thick translucent Mylar strip (KerrHawe SA, Bioggio, Switzerland) in order to create a smooth surface and to prevent the formation of an oxygen inhibited layer. Specimens of each composite resin group were subjected to one of the three aging conditions: (1) 5,000 thermocycles in water from $5^{\circ} \mathrm{C}$ to $55^{\circ} \mathrm{C}$ with a dwell time of $30 \mathrm{~s}$ at each temperature and a transfer time from one water bath to the other of $5 \mathrm{~s}$ (Willytec $\mathrm{GmbH}$, Gräfelfing, Germany); (2) immersion in deionized water at $37^{\circ} \mathrm{C}$ during 6 months; (3) immersion in citric acid ( $\left.\mathrm{pH} 3.0\right)$ at $37^{\circ} \mathrm{C}$ during 1 week. A non-aged group acted as the control.

After aging, the composite resin surfaces were conditioned with one of the following two procedures:

Intermediate adhesive resin (intermediate adhesive resin application (IAR-application)) Intermediate adhesive resins (IARs) of the corresponding composite resins (Table 1) were applied in a thin layer on the substrates using a microbrush. Subsequently, the solvent was gently airthinned under oil-free compressed air and finally photopolymerized according to each manufacturer's instructions.

Tribochemical silica coating (specific IAR-application (SCapplication)) A silica coating (see also Table 1) was applied using an intraoral air abrasion device (DentoPrep $^{\text {TM }}$, RØNVIG A/S, Daugaard, Denmark) filled with $30-\mu \mathrm{m}$ alumina particles coated with silica from a distance of approximately $10 \mathrm{~mm}$ at a pressure of 2.5 bars for $4 \mathrm{~s}$. Following surface conditioning, loose particles were gently air blown. The conditioned substrates were then coated with a 3-methacryloxypropyltrimethoxysilane coupling 
Table 1 Product and company names, chemical compositions, abbreviations, and batch numbers of the materials used in this study

\begin{tabular}{|c|c|c|c|c|}
\hline Product name & Company name & Chemical composition & Abbreviations & Batch number \\
\hline \multicolumn{5}{|l|}{ Composite resin } \\
\hline $\begin{array}{l}\text { Quadrant Anterior } \\
\text { Shine (microhybrid) }\end{array}$ & $\begin{array}{l}\text { Cavex BV, } \\
\text { Haarlem, } \\
\text { The Netherlands }\end{array}$ & $\begin{array}{l}\text { Bisphenolglycidil methacrylate (Bis-GMA), diurethane } \\
\text { dimethacrylate (DUDMA), silica, silicate glass, } \\
\text { Ba-glass, fluoride-containing fillers (63 vol. } \%)\end{array}$ & AS & 010100 \\
\hline Grandio (nanohybrid) & $\begin{array}{l}\text { Voco GmbH, } \\
\text { Cuxhaven, Germany }\end{array}$ & $\begin{array}{l}\text { Bis-GMA, urethane dimethacrylate (UDMA), triethylene } \\
\text { glycol methacrylate (TEGMA), glass-ceramic, } \\
\mathrm{SiO}_{2} \text {-containing fillers }(71.4 \quad \text { vol. } \%)\end{array}$ & G & 621332 \\
\hline $\begin{array}{l}\text { Tetric Evo Ceram } \\
\text { (nanohybrid) }\end{array}$ & $\begin{array}{l}\text { Ivoclar Vivadent } \\
\text { AG, Schaan, } \\
\text { Liechtenstein }\end{array}$ & $\begin{array}{l}\text { Bis-GMA, triethylene glycol dimethacrylate } \\
\text { (TEGDMA), urethane dimethacrylate (UDMA), } \\
\text { Ba-Al-F-B-silicate, } \mathrm{SiO}_{2} \text {, mixed oxide, } \\
\text { YbF3-containing fillers }(48.5 \text { vol.\%) }\end{array}$ & $\mathrm{TE}$ & J04088 \\
\hline $\begin{array}{l}\text { Filtek Supreme } \\
\text { XT (nanofilled) }\end{array}$ & $\begin{array}{l}\text { 3M ESPE, St. } \\
\text { Paul, MN, USA }\end{array}$ & $\begin{array}{l}\text { TEGDMA, UDMA, ethoxylated bisphenolglycidil } \\
\text { methacrylate (Bis-EMA), zirconia-silica, } \\
\text { silica-containing fillers ( } 57.7 \text { vol. } \%)\end{array}$ & FS & $6 \mathrm{BG}$ \\
\hline \multicolumn{5}{|c|}{ Tribochemical Silica Coating Kit (for SC-application) } \\
\hline CoJet $^{\circledR}$-Sand & $\begin{array}{l}\text { 3M ESPE AG, } \\
\text { Seefeld, Germany }\end{array}$ & $\begin{array}{l}\text { Aluminum trioxide particles coated with silica, } \\
\text { particle size } 30 \mu \mathrm{m}\end{array}$ & $\mathrm{SC}$ & 165092 \\
\hline $\mathrm{ESPE}^{\circledR}-\mathrm{Sil}$ & $\begin{array}{l}\text { 3M ESPE AG, } \\
\text { Seefeld, Germany }\end{array}$ & 3-Methacryloxypropyltrimethoxysilane, ethanol & Silane & 152745 \\
\hline \multicolumn{5}{|c|}{ Intermediate Adhesive Resin (for IAR-application) } \\
\hline $\begin{array}{l}\text { Visio }{ }^{\mathrm{TM}} \text {-Bond } \\
\text { (for tribochemical } \\
\text { silica coating } \\
\text { treatment) }\end{array}$ & $\begin{array}{l}\text { 3M ESPE AG, } \\
\text { Seefeld, Germany }\end{array}$ & $\begin{array}{l}\text { Dicyclopentyldimethylene diacrylate, } \\
\text { 2-propenoic acid, 2-methyl,2-(2-hydroxylethyl) } \\
\text { (3-methoxypropyl) (aminoP ethyl ester) }\end{array}$ & VB & 161808 \\
\hline $\begin{array}{l}\text { Quadrant Unibond } \\
\text { (for AS) }\end{array}$ & $\begin{array}{l}\text { Cavex BV, } \\
\text { Haarlem, } \\
\text { The Netherlands }\end{array}$ & $\begin{array}{l}\text { Bis-GMA, TEGDMA, silicate glass fillers, silica, } \\
\text { polycarboxylic acid, champorquinone }\end{array}$ & Q & 010049 \\
\hline $\begin{array}{l}\text { Solobond Plus } \\
\text { (for G) }\end{array}$ & $\begin{array}{l}\text { Voco GmbH, } \\
\text { Cuxhaven, Germany }\end{array}$ & Bis-GMA, TEGDMA, HEMA, champorquinone & $\mathrm{S}$ & 591583 \\
\hline Multilink (for TE) & $\begin{array}{l}\text { Ivoclar Vivadent } \\
\text { AG, Schaan, } \\
\text { Liechtenstein }\end{array}$ & $\begin{array}{l}\text { Primer A: Water, initiators (sulfonate, amines); } \\
\text { primer B: phosphonic acid acrylate, HEMA, } \\
\text { TEGDMA, methacrylate modified polyacrylic acid }\end{array}$ & M & $\begin{array}{l}\text { Primer A: H10145; } \\
\text { primer B: } 09713\end{array}$ \\
\hline $\begin{array}{l}\text { Adper Scotchbond } \\
\text { 1XT (for FS) }\end{array}$ & $\begin{array}{l}\text { 3M ESPE, St. Paul, } \\
\text { MN, USA }\end{array}$ & $\begin{array}{l}\text { Dimethacrylate, HEMA, polyalcenoic acid } \\
\text { copolymer, silane treated colloidal silica, } \\
\text { ethanol, water, photoinitiator }\end{array}$ & A & $4 \mathrm{BM}$ \\
\hline
\end{tabular}

agent, $\gamma$-MPS, allowing 5 min for its reaction. Finally, an intermediate adhesive resin, specific to the silica coating procedure, was applied with a microbrush, air thinned, and photo-polymerized for $20 \mathrm{~s}$. The entire procedure described above will be referred to in this manuscript as SC-application.

Repair bond strengths and failure analysis

Following surface conditioning, composite resins of the same kind as their substrates were adhered onto the conditioned substrates using translucent polyethylene molds (inner diameter $3.6 \mathrm{~mm}$, height $5 \mathrm{~mm}$ ). The composite resin was placed against the substrate incrementally with a hand instrument and photo-polymerized in two layers with a thickness of less than $2 \mathrm{~mm}$. Each layer was polymerized according to manufacturer's instruction, from a distance of $2 \mathrm{~mm}$ from the mold. After polymerization, specimens were gently removed from the polyethylene molds.
Specimens were secured in a mounting jig of a universal testing machine (ROELL Z2.5 MA 18-1-3/7, Zwick $\mathrm{GmbH}$, Ulm, Germany). The force was applied at the adhesive interface using a semicircular blade with $45^{\circ}$ inclination at the tip, fitting around the cylindrical composite specimen, at a cross-head speed of $1 \mathrm{~mm} / \mathrm{min}$ until failure. The mode of failure was determined under optical light microscopy (MP 320, Carl Zeiss GmbH, Jena, Germany) at a $\times 40$ magnification and recorded as cohesive in the substrate, appearing as small indents or as adhesive failure at the interface showing a completely smooth surface.

\section{Surface characterization}

For surface characterization, composite blocks $(5 \times 6 \times 6 \mathrm{~mm})$ were produced, as described above.

Elemental compositions of the outermost composite surfaces can be determined quantitatively by X-ray photoelectron spectroscopy and used to model the surface. In this 


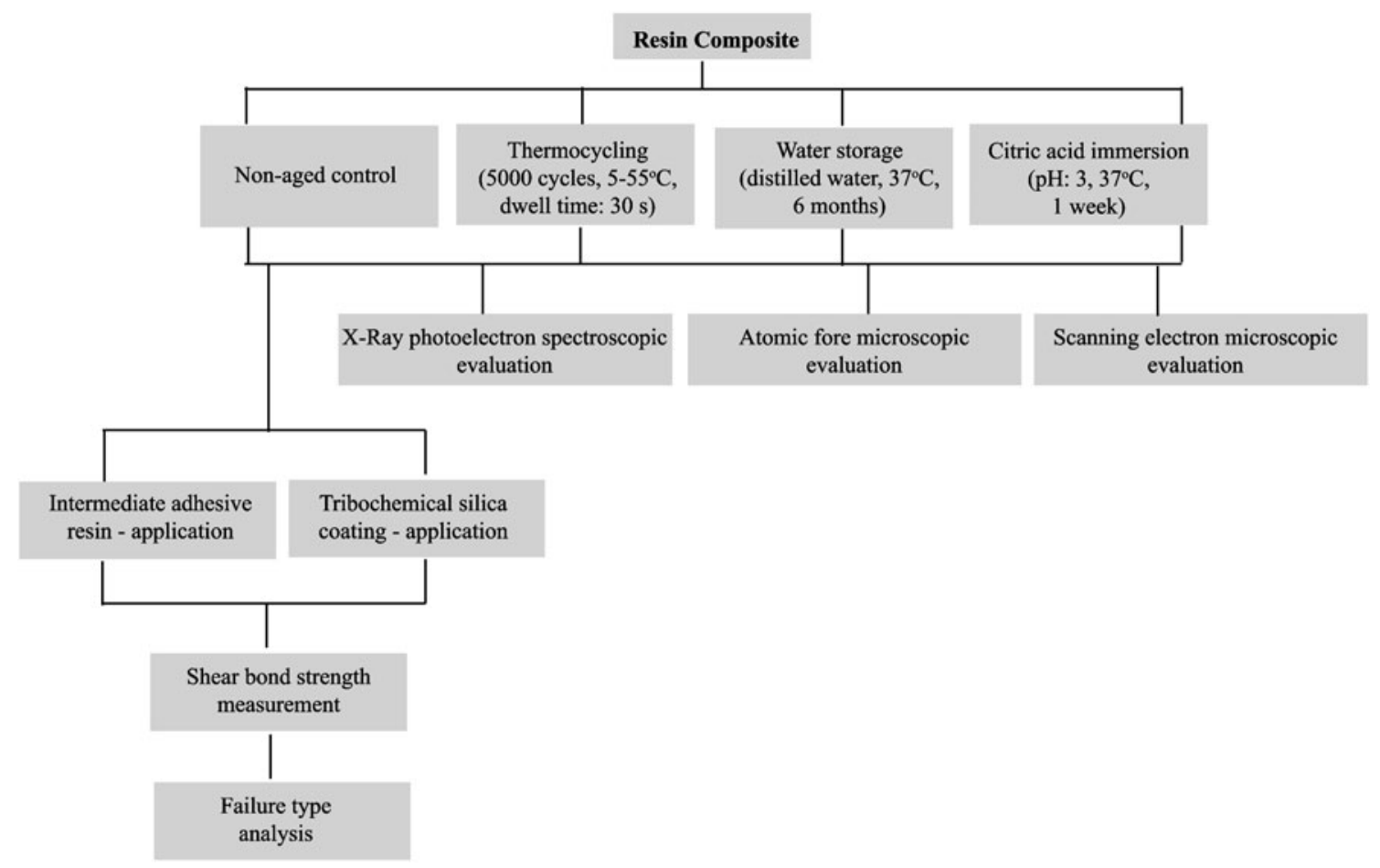

Fig. 1 Flow diagram of the experimental design and techniques applied

study, X-ray photoelectron spectroscopy was performed using an S-Probe spectrometer (Surface Science Instruments, Mountain View, CA, USA) equipped with an aluminum anode $(10 \mathrm{kV}, 22 \mathrm{~mA})$ and a quartz monochromator. The direction of the photoelectron collection angle to the specimens was $55^{\circ}$, and the electron flood gun was set at $10 \mathrm{eV}$. A survey scan was made with a $1,000 \times 259-\mu \mathrm{m}$ spot and pass energy of $50 \mathrm{eV}$. Binding energies were determined by setting the binding energy of the $\mathrm{C}_{1 \mathrm{~s}}$ component due to carbon-carbon bonds at $284.8 \mathrm{eV}$.
X-ray photoelectron spectroscopy data were used to model the composite surface in terms of its filler exposure. For a fully resin matrix-covered surface, the molecular structure of the resin yields a theoretical value $(\mathrm{O} / \mathrm{C})_{\text {theoretical }}$ that can be compared with the experimental value for $(\mathrm{O} / \mathrm{C})_{\text {experimental }}$. Since the experimental value for $(\mathrm{O} / \mathrm{C})$ is due to the resin matrix and silica-containing filler particles, the experimental values for $(\mathrm{O} / \mathrm{C})_{\text {experimental }}$ can be expressed in a matrix part $(\mathrm{O} / \mathrm{C})_{\text {matrix }}$ by subtracting the oxygen arising from silica (for $\mathrm{SiO} 2$, this involves subtracting twice the amount of

Table 2 Mean repair bond strengths (megapascals) for the four different composite resins after different aging conditions

\begin{tabular}{|c|c|c|c|c|c|c|c|c|}
\hline \multirow[t]{2}{*}{ Composite } & \multicolumn{4}{|c|}{ After IAR-application } & \multicolumn{4}{|c|}{ After SC-application } \\
\hline & $\begin{array}{l}\text { Non-aged } \\
\text { control }\end{array}$ & Thermocycling & $\begin{array}{l}\text { Water } \\
\text { storage }\end{array}$ & $\begin{array}{l}\text { Citric acid } \\
\text { immersion }\end{array}$ & $\begin{array}{l}\text { Non-aged } \\
\text { control }\end{array}$ & Thermocycling & Water storage & $\begin{array}{l}\text { Citric acid } \\
\text { immersion }\end{array}$ \\
\hline AS & $19.8 \pm 4.6 \mathrm{a}, \mathrm{A}$ & $2.8 \pm 0.8^{\mathrm{a}, \mathrm{B}}$ & $3.8 \pm 2.6 \mathrm{a}, \mathrm{B}$ & $13.8 \pm 6.4 \mathrm{a}, \mathrm{C}, \mathrm{E}$ & $\begin{array}{l}23.2 \pm 1.3 \mathrm{a} \\
\text { A, D }\end{array}$ & $18.7 \pm 6.7 \mathrm{a}, \mathrm{b}, \mathrm{A}$ & $28.3 \pm 7.4 \mathrm{a}, \mathrm{D}$ & $11.4 \pm 4.0 \mathrm{a}, \mathrm{E}$ \\
\hline G & $31.8 \pm 5.7 \mathrm{~b}, \mathrm{~A}$ & $10.4 \pm 3.8 \mathrm{~b}, \mathrm{~B}$ & $12.7 \pm 3.7 \mathrm{~b}, \mathrm{~B}$ & $13.7 \pm 3.3 \mathrm{a}, \mathrm{B}$ & $32.2 \pm 4.2 \mathrm{~b}, \mathrm{~A}$ & $23.0 \pm 8.0 \mathrm{a}, \mathrm{C}$ & $45.2 \pm 5.0 \mathrm{~b}, \mathrm{D}$ & $\begin{array}{c}13.8 \pm 3.1 \mathrm{a} \\
\mathrm{b}, \mathrm{B}\end{array}$ \\
\hline $\mathrm{TE}$ & $22.2 \pm 6.5 \mathrm{a}, \mathrm{A}$ & $11.9 \pm 2.4 \mathrm{~b}, \mathrm{~B}, \mathrm{E}$ & $\begin{array}{c}8.4 \pm 4.6 \mathrm{a} \\
\mathrm{b}, \mathrm{B}\end{array}$ & $\begin{array}{l}18.0 \pm 7.1 \mathrm{a}, \mathrm{b} \\
\mathrm{A}, \mathrm{F}\end{array}$ & $\begin{array}{c}20.0 \pm 5.2 \mathrm{a} \\
\mathrm{A}, \mathrm{C}\end{array}$ & $\begin{array}{l}16.9 \pm 6.5 \mathrm{~b}, \mathrm{C} \\
\mathrm{E}, \mathrm{F}\end{array}$ & $32.2 \pm 8.3 \mathrm{a}, \mathrm{D}$ & $11.23 .9 \mathrm{a}, \mathrm{B}$ \\
\hline $\mathrm{FS}$ & $\begin{array}{c}27.6 \pm 6.6 \mathrm{~b} \\
\mathrm{~A}, \mathrm{C}\end{array}$ & $7.1 \pm 3.1 \mathrm{a}, \mathrm{b}, \mathrm{B}$ & $13.0 \pm 8.1 \mathrm{~b}, \mathrm{E}$ & $23.0 \pm 9.8 \mathrm{~b}, \mathrm{C}, \mathrm{F}$ & $29.2 \pm 6.4 \mathrm{~b}, \mathrm{~A}$ & $\begin{array}{l}20.9 \pm 7.1 \mathrm{a}, \mathrm{b} \\
\mathrm{D}, \mathrm{F}\end{array}$ & $\begin{array}{l}21.7 \pm 8.6 \mathrm{c} \\
\mathrm{D}, \mathrm{F}\end{array}$ & $\begin{array}{l}17.5 \pm 6.9 \mathrm{~b} \\
\mathrm{D}, \mathrm{E}\end{array}$ \\
\hline
\end{tabular}

Composite surfaces were either conditioned application of an intermediate adhesive resin (IAR) or silica coating (SC). \pm denotes standard deviations over ten specimens. For abbreviations see Table 1

Same lowercase letters indicate an insignificant difference between the row; same uppercase letters denote an insignificant difference between the column 
measured Si from the amount of measured O). Subsequently, the fraction of the surface covered by filler particles can be derived from

$f_{\text {filler }}=1-(\mathrm{O} / \mathrm{C})_{\text {matrix }} /(\mathrm{O} / \mathrm{C})_{\text {theoretical }}$

Surface roughness can be calculated from three-dimensional topographic images produced by atomic force microscopy. The atomic force microscope (Nanoscope IIIa Dimension ${ }^{\mathrm{TM}} 3100$, Digital Instruments, Santa Barbara, CA, USA) was operated in the contact mode, using a $\mathrm{Si}_{3} \mathrm{~N}_{4}$ cantilever tip (DNP from Veeco, Woodbury, NY) with a spring constant of $0.06 \mathrm{~N} / \mathrm{m}$. The composite resin was placed on a glass slide using doublesided sticky tape. Specimens were placed below the cantilever of the atomic force microscope to obtain three-dimensional images $(70 \times 70 \mu \mathrm{m})$ of the surface at three randomly selected positions on each specimen from which the average surface roughness was calculated.

A cold field emission scanning electron microscope (JSM6301F, Jeol Instruments, Tokyo, Japan) was used to image the morphology of the composite surfaces prior to and after aging. Images were taken at $25 \mathrm{kV}$ at a magnification of $\times 10,000$. Surfaces were first sputter-coated with gold/palladium (80/20) prior to examination.

\section{Statistical analysis}

Statistical analysis was performed with the SPSS software package (version 14.0; SPSS, Chicago, IL, USA). The results of the normality and homogeneity test (KolmogorovSmirnov) indicated that the residual values were normally distributed when plotted against predicted values. Effects of composite types, surface conditioning procedures, and aging methods on bond strengths were compared using three-way analysis of variance (ANOVA) and least significant difference (LSD) post hoc tests. The differences in surface roughness were analyzed using Mann-Whitney $U$ test. In all comparisons, statistical significance was accepted if the $p$ value was less than 0.05 .

\section{Results}

Bond strength and failure types

The shear bond strengths of the composite resins are shown in Table 2. Three-way ANOVA indicated significant effects $(p<$ 0.05 ) of composite types, surface conditioning procedures, and aging methods on repair bond strengths. Significant interactions were identified between composite types with surface conditioning procedures, composite types with aging methods, and surface conditioning procedures with aging method. LSD post hoc tests showed that bond strengths after intermediate IAR-application were significantly lower in aged composite resins than in non-aged control ones $(p<0.05)$, except for TE and FS after aging in citric acid. SCapplication, however, led to significantly higher bond strengths than IAR-application, especially after water storage. Regardless of the composite type, SC-application yielded more cohesive failures in the substrate $(70 \%, 88 \%$, and $70 \%$ for thermocycling, water storage, and citric acid immersion,
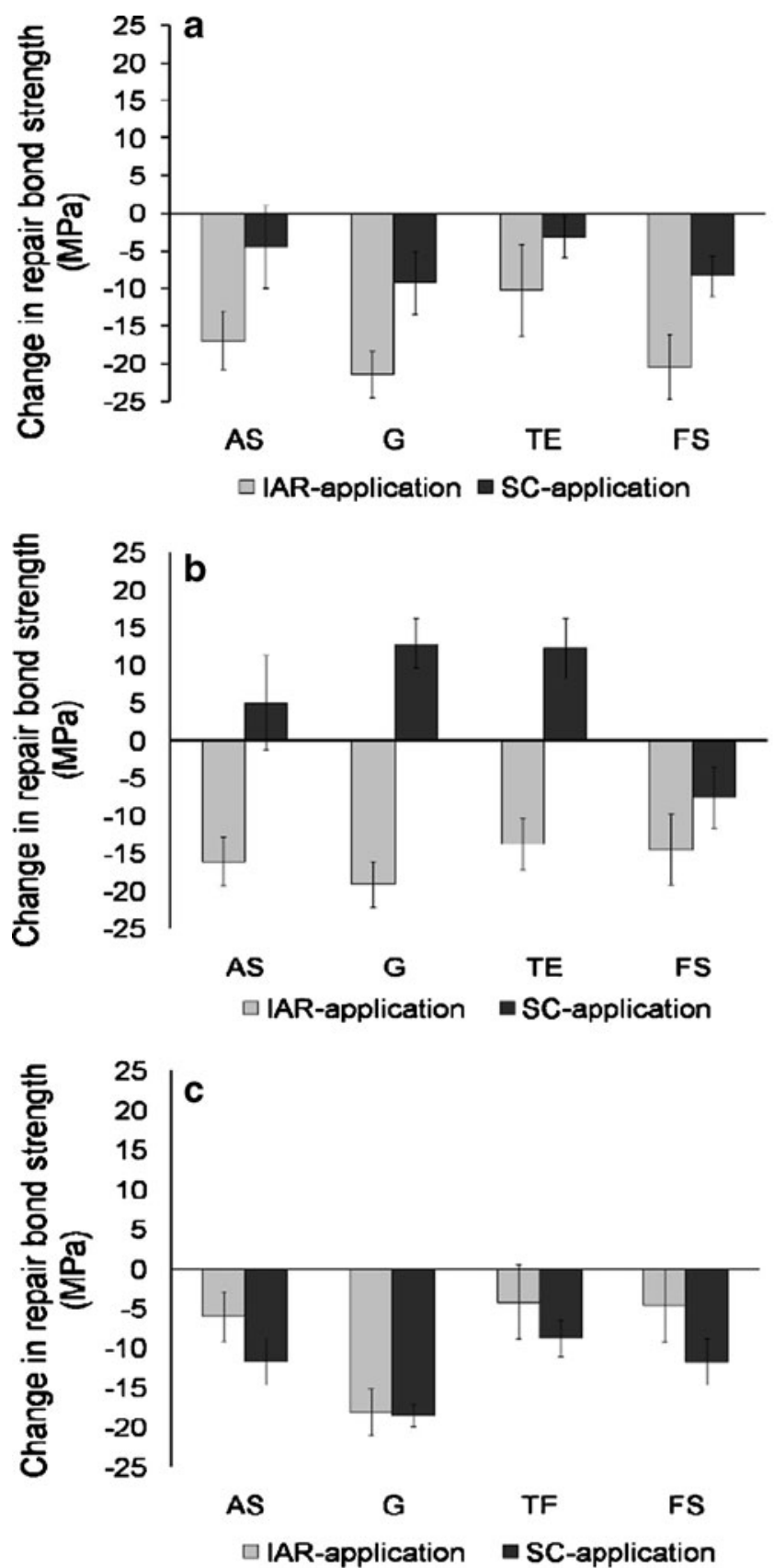

Fig. 2 a-c Changes in repair bond strengths with respect to non-aged controls for the four composite resins involved in this study, following conditioning using either IAR- or SC-application and after a thermocycling, b water storage, and c citric acid immersion. Error bars denote the SD over ten different specimens per group 
Table 3 Mean surface roughness (nanometer) of the four composite resins after different aging conditions

\begin{tabular}{|c|c|c|c|c|c|c|c|c|}
\hline \multirow{2}{*}{ Composite } & \multicolumn{4}{|c|}{ Prior to silica coating } & \multicolumn{4}{|c|}{ After silica coating } \\
\hline & Non-aged control & Thermocycling & Water storage & $\begin{array}{l}\text { Citric acid } \\
\text { immersion }\end{array}$ & $\begin{array}{l}\text { Non-aged } \\
\text { control }\end{array}$ & Thermocycling & Water storage & $\begin{array}{l}\text { Citric acid } \\
\text { immersion }\end{array}$ \\
\hline AS & $9 \pm 1$ & $37 \pm 6$ & $54 \pm 21$ & $39 \pm 18$ & $409 \pm 26$ & $510 \pm 69$ & $360 \pm 14$ & $335 \pm 12$ \\
\hline G & $7 \pm 1$ & $43 \pm 17$ & $53 \pm 7$ & $20 \pm 12$ & $351 \pm 24$ & $511 \pm 29$ & $392 \pm 13$ & $342 \pm 41$ \\
\hline $\mathrm{TE}$ & $8 \pm 3$ & $79 \pm 13$ & $30 \pm 5$ & $25 \pm 2$ & $346 \pm 15$ & $494 \pm 124$ & $378 \pm 13$ & $364 \pm 8$ \\
\hline FS & $4 \pm 1$ & $65 \pm 24$ & $41 \pm 7$ & $22 \pm 5$ & $411 \pm 18$ & $463 \pm 74$ & $418 \pm 20$ & $329 \pm 111$ \\
\hline
\end{tabular}

Surface roughness was measured prior to and after silica coating. \pm denotes standard deviations over three specimens. For abbreviations, see Table 1

respectively) than after application of the corresponding IARs (5\%, 15\%, and 48\% for thermocycling, water storage, and citric acid immersion, respectively).

The changes in bond strengths after aging with respect to those of the non-aged controls are presented in Fig. 2. IARapplication on aged composite resins did not improve the repair bond strengths to the level obtained in the non-aged controls, regardless of the aging method and type of composite resin involved. Also, SC-application did not restore bond strengths of composite surfaces aged by thermocycling and citric acid immersion to the level of non-aged controls, but it did improve the bond strength after water storage (except for FS).

Surface analysis

The roughness of the non-aged controls ranged between 4 and $9 \mathrm{~nm}$ and increased significantly $(p<0.05)$ after aging by a factor of 5 to 10 (19 to $79 \mathrm{~nm})$, as can be seen in Table 3. Subsequent SC-application yields another significant increase by a factor of $10(p<0.05)$. However, the effects of silica coating are variable, depending on the aging condition. Thermocycling generally yields significantly higher surface roughness than the non-aged control, whereas after water storage and citric acid immersion, similar roughness is observed as for the non-aged control.
The percentage filler exposure at the composite surfaces prior to and after aging is presented in Table 4 for non-aged and aged composite resins. Thermocycling and citric acid immersion increased filler particle exposure at the surface in all composite types with respect to the non-aged control. Water storage showed only minor effects on filler exposure, except for AS, which was the only composite type showing a lower filler exposure after water storage.

Scanning electron micrographs of composite surfaces prior to aging show scattered white regions, probably indicative of filler particles covered by a thin layer of matrix. All aging conditions clearly roughen the surface, as illustrated in Fig. 3 for the nanohybrid composite resin G.

\section{Discussion}

The durability of composite-to-composite repair bonding depends on the adhesion between the polymerized substrate and the adhering composite resin. The aging condition of the substrate may affect the strength of the adhesive joint. In this manuscript, we evaluated the effects of composite type, surface conditioning procedure, and aging method on the repair bond strengths of microhybrid, nanohybrid, and nanofilled composite resins and analyzed surface properties of the composite resins after aging. The results indicated

Table 4 Filler exposure at the composite surface prior to and after different aging conditions, calculated from X-ray photoelectron spectroscopic (XPS) analyses and comparison to the bulk filler composition provided by the manufacturers

\begin{tabular}{lccccc}
\hline Composite resin & \multicolumn{2}{l}{ Filler exposure at the surface from XPS (\%) } & $\begin{array}{c}\text { Bulk filler composition (vol.\%) } \\
\text { according to the manufacturer }\end{array}$ \\
\cline { 2 - 5 } & Non-aged control & Thermocycling & Water storage & Citric acid immersion & 63 \\
\hline AS & 20 & 22 & 7 & 25 & 71 \\
G & 27 & 56 & 21 & 64 & 48 \\
TE & 41 & 60 & 40 & 68 & 58 \\
FS & 14 & 49 & 24 & & 63 \\
\hline
\end{tabular}

For abbreviations, see Table 1 

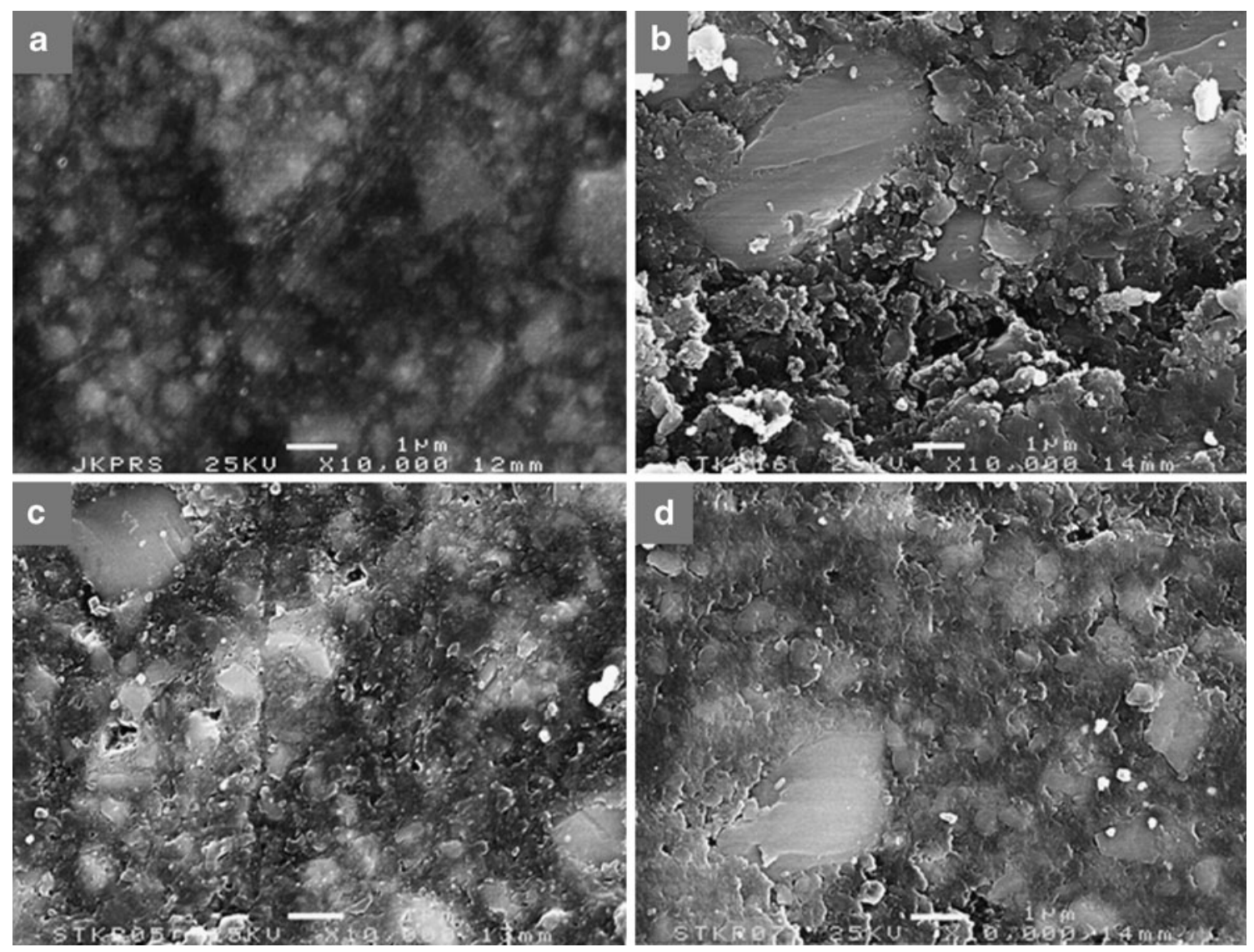

Fig. 3 a-d Representative scanning electron micrographs of the nanohybrid composite resin, Grandio. a Non-aged control, b after thermocycling, c after water storage, and $\mathbf{d}$ after citric acid immersion. Bar marker indicates $1 \mu \mathrm{m}$

that composite type, surface conditioning procedure, and aging method all influenced the repair bond strengths and the prevalence of cohesive failure. Since the interaction terms were also significant, the null hypothesis tested that aging conditions decrease the repair bond strength in all types of composites can only be accepted partially.

In vitro, analysis of composite-to-composite bonding can be done either by applying a shear or microtensile forces. Shear bond strength evaluation requires easier specimen preparation and alignment during measurement than microtensile bond strength measurement [29]. However, shear bond strength evaluation has been suggested to be less reliable than microtensile bond strength evaluation [30], because the adhesive interface in microtensile bond strength analysis is relatively small, invoking a more uniform stress distribution and therewith allowing better access to the true interfacial bond strength. To date, there is no consensus on whether the strength of composite-to-composite bonding should be evaluated in a shear or microtensile mode, although it can be argued that clinically, in the repair of composite restorations, applied forces are predominantly in the shear mode, as applied here.

Previously [31], we have extensively discussed the effects of IAR- and SC-application in immediate repair, i.e., in non- aged composite resins. SC-application was found to create significantly higher bond strengths than IAR-application in all four composite resins. Also in the current study, repair bond strengths of non-aged composite resins after SC-application were slightly higher or similar than after IAR-application but not to the extent as seen before. In repair after aging of a composite resin, simulated here by three different aging methods, neither IAR- nor SC-application was generally able to create bond strengths comparable to the ones observed in immediate repair, i.e., non-aged controls in the current study, although it is known that different aging methods degrade the composite surface in different ways. In this respect, it is interesting that water storage followed by SC-application was the only combination studied that yielded an increase in bond strength with respect to non-aged controls (see Fig. 2b). Hypothetically, we attribute this to increased capture of silica particles by the softened resin matrix.

Thermocycled specimens have been subjected to temperature fluctuations, generating thermal stresses and leading to microcracks in the matrix or failure at the filler/matrix interface $[22,23]$. Moreover, exposure to water may cause hydrolytic degradation of filler's silane coating [23, 32] or swelling of the matrix [33]. Filler exposure after thermocycling never decreased in the current study, regardless of the 
composite type, indicating that particle detachment is highly unlikely. Differences in filler exposure after thermocycling are thus most likely due to matrix degradation, leading to exposure of underlying filler particles and an increased surface roughness. Composite resins containing hydrophilic components, like TEGDMA or TEGMA as a matrix (G, TE, and FS), may be more susceptible to matrix degradation [32] than AS, lacking TEGDMA or TEGMA that enable easier water penetration due to their hydrophilicity.

There is limited information about the effect of citric acid immersion on composite degradation. Aging in citric acid takes place at a low $\mathrm{pH}$ and in an aqueous environment, but at the same time, it lacks temperature fluctuations as in thermocycling. Yet, citric acid immersion had similar effects on filler particle exposure than thermocycling but caused a smaller increase in surface roughness. Thus, whereas matrix degradation due to fluctuating temperatures is the likely cause for increased filler particles exposure after thermocycling, citric acid may cause matrix degradation by the same effects. Water exposure causes an increase in surface roughness, which is probably more due to swelling rather than to matrix degradation, because filler particle exposure after water storage hardly increases.

The severe aging effects caused by aggressive thermocycling and citric acid immersion negatively impacted the repair bond strengths compared to non-aged composite resins, regardless of the composite type and conditioning applied. Similarly, IAR-application after water storage also had a negative impact on repair bond strengths, but surprisingly, SC-application after water storage yielded higher bond strengths for AS, G, and TE. Possibly, increased filler particle exposure as after thermocycling and citric acid immersion causes silica particles to bounce off the filler-dominated surfaces, whereas after water storage, causing predominantly swelling, the swelled matrix at the composite surface will yield increased capture of silica particles and a more positive effect of SC-application. Interestingly, SC-application did not give any benefit for FS aged by water storage.

Regardless of the aging method and composite type, cohesive failure in the substrate appeared much more frequent than adhesive failure after SC-application. IARapplication on aged composite resins resulted in more adhesive failures. The cohesive failures observed after SCapplication indicate that the adhesive strength at the interface exceeded the cohesive strength of the underlying composite resin, and thus, the repair as such cannot be considered the weakest link. Moreover, if a composite repair fractures cohesively in the substrate, one can assume that the approach selected for repair was appropriate to bear the occlusal loads [34]. Thus, based on failure type analysis, SC-application should generally be preferred for aged composite resins, although it has been argued that also a non-functional abrasive powder, such as $\mathrm{Al}_{2} \mathrm{O}_{3}$ may produce the same results [35]. However, it remains to be investigated whether the durability of the bond that can be obtained with a non-functional powder is equally high as observed for functionalized one. A silica-functionalized surface is chemically more reactive to the resin. Silane molecules react with water to form three silanol groups $(-\mathrm{Si}-\mathrm{OH})$ from the corresponding methoxy groups $\left(-\mathrm{Si}-\mathrm{O}-\mathrm{CH}_{3}\right)$. The silanol groups then react further to form a siloxane $(-\mathrm{Si}-\mathrm{O}-\mathrm{Si}-\mathrm{O}-)$ network with the silica surface. Monomeric ends of the silane molecules react with the methacrylate groups of the adhesive resins by a free radical polymerization process. Clearly, no siloxane network will form in case of a non-functional powder [36].

\section{Conclusions}

Thermocycling, water storage, and citric acid immersion affect the surface of composite resins with an impact on the repair bond strengths. Bond strength analysis is indecisive on whether aged composite resins should be repaired using IAR- or SC-application. Failure type analysis, however, strongly indicates that in general SC-application should be favored for the repair of aged composite resins.

Conflict of interest The authors declare that they have no conflict of interest.

Open Access This article is distributed under the terms of the Creative Commons Attribution Noncommercial License which permits any noncommercial use, distribution, and reproduction in any medium, provided the original author(s) and source are credited.

\section{References}

1. Tyas MJ, Anusavice KJ, Frencken JE, Mount GJ (2000) Minimal intervention dentistry - a review. FDI Commission Project 1-97. Int Dent J 50:1-12

2. White JM, Eakle WS (2000) Rationale and treatment approach in minimally invasive dentistry. J Am Dent Assoc 131(Suppl):13S-19S

3. Murdoch-Kinch MA, McLean ME (2003) Minimally invasive dentistry. J Am Dent Assoc 134:87-95

4. Akova T, Ozkomur A, Uysal H (2006) Effect of food-simulating liquids on the mechanical properties of provisional restorative materials. J Dent 22:1130-1134

5. Sarkar NK (2000) Internal corrosion in dental composite wear: its significance and simulation. J Biomed Mater Res B Appl Biomater 53:371-380

6. Mjor IA (1981) Placement and replacement of restorations. Oper Dent 6:49-54

7. Roulet JF (1988) The problems associated with substituting composite resins for amalgam: a status report on posterior composites. J Dent 16:101-113

8. Swift EJ (1987) Wear of composite resins in permanent posterior teeth. J Am Dent Assoc 115:584-588 
9. Lewis G, Johnson W, Martin W, Canerdy A, Claburn C, Collier M (1998) Shear bond strength of immediately repaired light-cured composite resin restorations. Oper Dent 23:121-127

10. Mjor IA, Moorhead JE, Dahl JE (1999) Selection of restorative materials in permanent teeth in general dental practice. Acta Odontol Scand 57:257-262

11. Papacchini F, DallÓca S, Chieffi N, Goracci C, Sadek FT, Suh BI, Tay FR, Ferrari M (2007) Composite-to-composite microtensile bond strength in the repair of a microfilled hybrid resin: effect of surface treatment and oxygen inhibition. J Adhes Dent 9:25-31

12. Bouschlicher MR, Reindhardt JW, Vargas MA (1997) Surface treatment techniques for resin composite repair. Am J Dent 10:279-283

13. Rosales-Leal JI, Osorio R, Holgadi-Terriza JA, Cabrrerizo-Vilches MA, Toledano M (2001) Dentin wetting by four adhesive systems. Dent Mater 17:526-532

14. Chiba K, Hosoda H, Fusayama T (1989) The addition of an adhesive composite resin to the same material: bond strength and clinical techniques. J Prosthet Dent 61:669-675

15. Özcan M, Barbosa S, Melo R, Galhano G, Bottino M (2007) Effect of surface conditioning methods on the microtensile bond strength of resin composite to composite after aging conditions. Dent Mater 23:1276-1282

16. Shahdad SA, Kennedy JG (1998) Bond strength of repaired anterior composite resins: an in vitro study. J Dent 26:685-694

17. Turner CW, Meiers JC (1993) Repair of an aged, contaminated indirect composite resin with a direct, visible-light-cured composite resin. Oper Dent 18:187-194

18. Swift EJ, Le Valley BD, Boyer DB (1992) Evaluation of new methods for composite repair. Dent Mater 8:362-365

19. Cesar P, Meyer Faara P, Miwa Caldart R, Gastaldoni Jaeger R, da Cunha RF (2001) Tensile bond strength of composite repairs on Artglass using different surface treatments. Am J Dent 14:373-377

20. Frankenberger R, Kramer N, Sindel J (2000) Repair strength of etched vs silica-coated metal-ceramic and all-ceramic restorations. Oper Dent 25:209-215

21. Yap AUJ, Sau CW, Lye KW (1999) Effects of aging on repair bond strengths of a polyacid-modified composite resin. Oper Dent 24:371-376

22. Hakimeh S, Vaidyanathan J, Houpt ML, Vaidyanathan TK, Von Hagen S (2000) Microleakage of compomer class V restorations: effect of load cycling, thermal cycling, and cavity shape differences. J Prosthet Dent 83:194-203
23. Kawano F, Ohguri T, Ichikawa T, Matsumoto N (2001) Influence of thermal cycles in water on flexural strength of laboratoryprocessed composite resin. J Oral Rehabil 28:703-707

24. Cattani-Lorente M, Dupuis V, Moya F, Payan J, Meyer JM (1999) Comparative study of the physical properties of a polyacidmodified composite resin and a resin-modified glass ionomer cement. Dent Mater 15:21-32

25. Soderholm KJ, Zigan M, Ragan M, Fischlschweiger W, Bergman M (1984) Hydrolytic degradation of dental composites. J Dent Res 63:1248-1254

26. Crim GA, Garcia-Godoy F (1987) Microleakage: the effect of storage and cycling duration. J Prosthet Dent 57:574-576

27. Brentel AS, Ozcan M, Valandro LF, Alarca LG, Amaral R, Bottino MA (2007) Microtensile bond strength of a resin cement to feldpathic ceramic after different etching and silanization regimens in dry and aged conditions. Dent Mater 23:1323-1331

28. Padipatvuthikul P, Mair LH (2007) Bonding of composite to water aged composite with surface treatments. Dent Mater 23:519 525

29. Rasmussen S (1996) Analysis of dental shear bond strength tests, shear or tensile. Int J Adhesion and Adhesives 16:147-154

30. Della BA, Anusavice K, Shen C (2000) Microtensile strength of composite bonded to hot-pressed ceramics. J Adhes Dent 2:305313

31. Rinastiti M, Ozcan M, Siswomihardjo W, Busscher HJ (2009) Immediate repair bond strengths of microhybrid, nanohybrid and nanofilled composites after different surface treatments. J Dent 38:29-38

32. Örtengren U, Andersson F, Elgh U, Terselius B, Karlsson S (2001) Influence of $\mathrm{pH}$ and storage time on the sorption and solubility behaviour of three composite resin materials. J Dent 29:35-41

33. McCabe JF, Rusby S (2004) Water absorption, dimensional change and radial pressure in resin matrix dental restorative materials. Biomaterials 25:4001-4007

34. Lucena-Martin C, Lopez S, de Mondelo J (2001) The effect of various surface treatments and bonding agents on the repaired strength of heat-treated composites. J Prosthet Dent 86:481-488

35. Rathke A, Tymina Y, Haller B (2009) Effect of different surface treatments on the composite-composite repair bond strength. Clin Oral Invest 13:317-323

36. Özcan M, Vallittu PK (2003) Effect of surface conditioning methods on the bond strength of luting cement to ceramics. Dent Mater 19:725-731 